\title{
Premature birth and circadian preference in young adulthood : evidence from two birth cohorts
}

\section{Björkqvist, Johan}

\section{8}

Björkqvist , J , Pesonen, A-K, Kuula , L , Matinolli , H-M , Lano , A , Sipola-Leppanen , M , Tikanmaki , M , Wolke , D , Jarvelin , M-R , Eriksson, J G , Andersson , S , Vaarasmaki , M , Heinonen , K, Raikkonen , K , Hovi , P \& Kajantie , E 2018 , ' Premature birth and circadian preference in young adulthood : evidence from two birth cohorts ', Chronobiology International , vol. 35 , no. 4 , pp. 555-564 . https://doi.org/10.1080/07420528.2017.1420078

http://hdl.handle.net/10138/302026

https://doi.org/10.1080/07420528.2017.1420078

unspecified

publishedVersion

Downloaded from Helda, University of Helsinki institutional repository.

This is an electronic reprint of the original article.

This reprint may differ from the original in pagination and typographic detail.

Please cite the original version. 
CHRONOBIOLOGY

INTERNATIONAL

1.

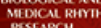

mischerch

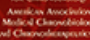

$x$

\section{Premature birth and circadian preference in young adulthood: evidence from two birth cohorts}

Johan Björkqvist, Anu-Katriina Pesonen, Liisa Kuula, Hanna-Maria Matinolli, Aulikki Lano, Marika Sipola-Leppänen, Marjaana Tikanmäki, Dieter Wolke, Marjo-Riitta Järvelin, Johan G Eriksson, Sture Andersson, Marja Vääräsmäki, Kati Heinonen, Katri Räikkönen, Petteri Hovi \& Eero Kajantie

To cite this article: Johan Björkqvist, Anu-Katrina Pesonen, Liisa Kuula, Hanna-Maria Matinolli, Aulikki Lano, Marika Sipola-Leppänen, Marjaana Tikanmäki, Dieter Wolke, MarjoRiitta Järvelin, Johan G Eriksson, Sture Andersson, Marja Vääräsmäki, Kati Heinonen, Katri Räikkönen, Petteri Hovi \& Eero Kajantie (2018) Premature birth and circadian preference in young adulthood: evidence from two birth cohorts, Chronobiology International, 35:4, 555-564, DOI: 10.1080/07420528.2017.1420078

To link to this article: https://doi.org/10.1080/07420528.2017.1420078

View supplementary material $₫$ Published online: 30 Jan 2018.

Submit your article to this journal 저

Џ Article views: 85

View related articles $\asymp$ 


\title{
Premature birth and circadian preference in young adulthood: evidence from two birth cohorts
}

\author{
Johan Björkqvist ${ }^{\mathrm{a}, \mathrm{b}}$, Anu-Katriina Pesonen ${ }^{\mathrm{c}}$, Liisa Kuulac, Hanna-Maria Matinollija, ${ }^{\mathrm{a},}$ Aulikki Lano ${ }^{\mathrm{b}}$, Marika Sipola- \\ Leppänen ${ }^{\mathrm{a}, \mathrm{d}, \mathrm{e}}$, Marjaana Tikanmäkij ${ }^{\mathrm{a}, \mathrm{d}}$, Dieter Wolkef, Marjo-Riitta Järvelin ${ }^{\mathrm{d}, \mathrm{g}}$, Johan G Eriksson ${ }^{\mathrm{a}, \mathrm{h}, \mathrm{i}, \mathrm{j}}$, \\ Sture Andersson $^{\mathrm{b}}$, Marja Vääräsmäkia,e, Kati Heinonenc, Katri Räikkönenc, Petteri Hovi ${ }^{\mathrm{a}, \mathrm{b}}$, and Eero Kajantie ${ }^{\mathrm{a}, \mathrm{b}, \mathrm{e}}$ \\ aDepartment of Public Health Solutions, National Institute for Health and Welfare, Helsinki and Oulu, Finland; 'bChildren's Hospital, University \\ of Helsinki and Helsinki University Hospital, Finland; 'Department of Psychology and Logopedics, Faculty of Medicine, University of Helsinki, \\ Finland; 'Institute of Health Sciences, University of Oulu, Oulu, Finland; ePEDEGO Research Unit, MRC Oulu, Oulu University Hospital and \\ University of Oulu, Oulu, Finland; fDepartment of Psychology, University of Warwick, Warwick, United Kingdom; ${ }^{9}$ School of Public Health, \\ Faculty of Medicine, Imperial College, London, United Kingdom; 'Department of General Practice and Primary Health Care, University of \\ Helsinki and Helsinki University Hospital, Helsinki, Finland; 'Vasa Central Hospital, Vasa, Finland; 'Folkhälsan Research Center, Helsinki, \\ Finland
}

\begin{abstract}
A preference for eveningness (being a "night owl") and preterm birth ( $<37$ weeks of gestation) are associated with similar adversities, such as elevated blood pressure, impaired glucose regulation, poorer physical fitness, and lower mood. Yet, it remains unclear if and how preterm birth is associated with circadian preference. The aim of this study was to assess this association across the whole gestation range, using both objective and subjective measurements of circadian preference.

Circadian preference was measured among 594 young adults (mean age 24.3 years, SD 1.3) from two cohorts: the ESTER study and the Arvo Ylppö Longitudinal Study. We compared 83 participants born early preterm ( $<34$ weeks) and 165 late preterm ( 34 to $<37$ weeks) with those born at term ( $\geq 37$ weeks, $n=346)$. We also compared very low birth weight (VLBW, $<1500 \mathrm{~g})$ participants with term-born controls. We obtained objective sleep data with actigraphs that were worn for a mean period of 6.8 (SD 1.4) nights. Our primary outcome was sleep midpoint during weekdays and weekend. The sleep midpoint is the half-way time between falling asleep and waking up, and it represents sleep timing. We also investigated subjective chronotype with the Morningness-Eveningness Questionnaire (MEQ) in 688 ( $n=138 / 221 / 329$ ) ESTER participants. The MEQ consists of 19 questions, which estimates the respondent to be of a "morning", "evening," or "intermediate" chronotype, based on the Morningness-Eveningness Score (MES). We analyzed the data from the actigraphs and the MES with three linear regression models, and analyzed distribution of the chronotype class with Pearson $\mathrm{X} 2$.

There were no consistent differences across the study groups in sleep midpoint. As compared with those born at term, the mean differences in minutes:seconds and 95\% confidence intervals for the sleep midpoint were: early preterm weekdays $11: 47$ (-8:34 to 32:08), early preterm weekend 4:14 $(-19: 45$ to $28: 13)$, late preterm weekdays $-10: 28(-26: 16$ to $5: 21)$, and late preterm weekend $-1: 29$ ( $-20: 36$ to $17: 37)$. There was no difference in sleep timing between VLBW-participants and controls either. The distribution of chronotype in the MEQ among all participants was $12.4 \%$ morningness, $65.4 \%$ intermediate, and $22.2 \%$ eveningness. The distribution of the subjective chronotype class did not differ between the three gestational age groups $(p=0.98)$. The linear regression models did not show any influence of gestational age group or VLBW status on the MES (all $p>0.5$ ).

We found no consistent differences between adults born early or late preterm and those born at term in circadian preference. The earlier circadian preference previously observed in those born smallest is unlikely to extend across the whole range of preterm birth.
\end{abstract}

\section{ARTICLE HISTORY}

Received 5 September 2017

Revised 14 December 2017

Accepted 18 December 2017

\section{KEYWORDS}

Preterm; Actigraphy; MEQ;

Chronotype

\section{Introduction}

The adversities of the $\sim 14.9$ million (Blencowe et al. 2012) infants who are born preterm every year are not limited to the perilous beginning of their lives. Studies have shown that adults born preterm ( $<37$ weeks), in particular those born very preterm ( $<32$ weeks) or with a very or extremely low birth weight (VLBW $<1500 \mathrm{~g}$ and ELBW $<1000 \mathrm{~g}$ ), have higher blood pressure (Hovi et al.

CONTACT Johan Björkqvist johan.bjorkqvist@helsinki.fi National Institute for Health and Welfare, Department of Public Health Solutions, PL 30, 00271 Helsinki, Finland

(6) Supplemental data for this article can be accessed here.

(c) 2018 Taylor \& Francis Group, LLC 
2016), higher prevalence of dysglycemia (Morrison et al. 2016), they exercise less (Kajantie et al. 2010), and some studies report more depression (Mathewson et al. 2017; Nosarti et al. 2012).

Recent studies have indicated that individual circadian preference is also associated with health and wellbeing. Later circadian preference (being a "night owl") has been linked to many of the same risk factors that are associated with prematurity: higher blood pressure (Merikanto et al. 2013a), higher prevalence of diabetes (Merikanto et al. 2013a), less physical activity (Wennman et al. 2015; Wong et al. 2015), and more depression (Merikanto et al. 2013b).

The similarity of outcomes originally raised the question of whether preterm birth is associated with later circadian preference. Intriguingly, the few studies that have studied this association, have suggested the opposite, as children and adults born preterm have shown an earlier circadian preference (being a "morning lark"). These studies have used both objective and subjective measurements, and they report findings from different age groups. Two actigraphy studies in a cohort of VLBW adults, performed at ages 22.5 and 25 years (Björkqvist et al. 2014; Strang-Karlsson et al. 2008), together showed an earlier bed time and getting up time in the VLBW-group. A cohort of 16-19-year-old adolescents born preterm (mean birth weight $1514 \mathrm{~g}$ and gestational age 31 weeks) displayed a similar finding with actigraphy and self-report (Hibbs et al. 2014). At younger ages, a one-night, in-home polysomnography study found that 6-13-year-olds born very preterm had 13 minutes earlier sleep onset time compared to controls, but they also had a trend toward longer sleep duration $(9.0 \mathrm{~h}$ versus $8.9 \mathrm{~h}$, $p=0.066$ ) (Maurer et al. 2016). Using actigraphy, even 12-month-old VLBW-infants born preterm have displayed earlier sleep onset and offset times than term-born controls (Asaka \& Takada 2010).

In studies exclusively measuring self-reported chronotype, VLBW-adults reported a propensity for morningness in the Morningness-Eveningness Questionnaire (MEQ) (Strang-Karlsson et al. 2010). Also, among 13-year-old preterms ( $<37$ weeks), a larger proportion were "morning types" compared to controls when assessed with the Junior MEQ and Junior Composite Scale (Natale et al. 2005). A Norwegian questionnaire study (Stangenes et al. 2017 ) of extremely preterm ( $<28$ weeks or ELBW) 11-year-olds displayed $0.4 \mathrm{~h}$ earlier bedtime, but correspondingly longer time in bed.

Most participants of the aforementioned studies are characterized by a very low birth weight and/or very short gestational age. However, most preterm infants, e.g. $>70 \%$ of those born in the US (Engle et al. 2007), are born late preterm ( 34 to $<37$ weeks of gestation). Late preterm population is also subject to increased morbidity, mortality (Crump et al. 2011; Engle 2011), and cardiometabolic risk (Sipola-Leppänen et al. 2014), however whether this is related to circadian preference is not known.

Accordingly, the aim of the current study was to investigate if adults born preterm across the whole gestation range have different circadian preference than controls. To determine circadian preference, we used actigraphs to measure objective sleep timing and the Morningness-Eveningness Questionnaire to measure subjective chronotype. Based on the previous studies, we hypothesized an earlier circadian preference among the preterm participants of two large birth cohorts.

\section{Materials and methods}

\section{Participants}

Two cohorts provided the participants for the present analysis: the ESTER study, and the Arvo Ylppö Longitudinal Study (AYLS) (Supplemental Figure 1). The 1980 subjects of the ESTER study (Preterm Birth and Early-Life Programming of Adult Health and Disease) come from two cohorts: 1) the Northern Finland Birth Cohort 1986 (49.8\%) born in 1985-1986, and 2) a cohort of participants born 1987-1989 (50.2\%) in the same area, identified via the Finnish Medical Birth Register. In 2009-2011, 753 subjects (38.0\%) participated in a clinical study at 23.3 (SD 1.3) years. The study is based in Northern Finland, between latitudes 63.9 to 70.0. Comparison of participants and non-participants has been described in detail previously (Sipola-Leppänen et al. 2015). Of the clinical study participants $330(43.8 \%)$ participated in the actigraphy study. After exclusion of participants with night shifts $(n=9)$, sickness during the sleep registration period ( $n=14$, of whom two also belonged to each other group) and insufficient amount of nights ( $<3$ nights, $n=18)$, the 
participant number was 291, with altogether 1890 measured nights.

Additionally, in the ESTER study, 690 participants filled in the Morningness-Eveningness Questionnaire (MEQ) (Horne \& Östberg 1976). Two participants returned incomplete questionnaires, leaving 688 available for analysis (Supplemental Table 1).

AYLS is a part of a multicenter follow-up study conducted in Uusimaa, Finland, and Bavaria, Germany, called the Bavarian-Finnish longitudinal study (Heinonen et al. 2008; Riegel et al. 1995; Salonen et al. 2015). Participants in Finland were recruited from a total of 15,311 deliveries in the seven maternity hospitals in Uusimaa province 1985-1986. The sample comprised 2193 infants, of whom 1535 were admitted to neonatal wards within obstetric units or transferred to the Neonatal Intensive Care Unit (NICU) of the Children's Hospital within 10 days of birth. An additional 658 non-hospitalized controls were prospectively recruited, from births after every second hospitalized infant in the three largest maternity hospitals of Uusimaa. Of the 2193 infants, 1913 subjects $(87.2 \%)$ could be traced as adults, and were invited to a follow-up study performed 2009-2012. A total of 1136 subjects (hospitalized $n=754$, controls $n=382,59.4 \%$ of the invited) participated at the mean age of 25.2 (SD 0.6) years. AYLS is based around Helsinki, at latitude 60.2. To evaluate the effects of preterm birth, we restricted the study to preterm adults $(n=175$, of whom 166 were hospitalized as described above), and corresponding term-born ( $\geq 37$ weeks) adults from the control group ( $n=314$ ), a sum of 489 participants. Of these 489 individuals, 340 (69.5\%) participated in the actigraphy study After exclusion of participants with night shifts $(n=14)$, sickness during the sleep registration period $(n=5)$, and insufficient amount of nights ( $<3$ nights, $n=18$ ), the participant amount was 303 with altogether 2128 measured nights.

Therefore, for the pooled actigraphy data, we had a final total of 594 participants (291 from ESTER and 303 from AYLS) available for sleep analysis. These participants wore the actigraph for a mean period of $6.8(\mathrm{SD}=1.4)$ nights (ESTER 6.5, AYLS 7.0). We compared these final 594 subjects, who provided actigraphy data, with non-actigraphy participants and those who were excluded in the process. Among the final total of actigraphy study subjects, there were less preterm participants and less current smokers, and the participants were 0.45 years older (all $p<0.014$ ). There was no statistically significant difference in maternal body mass index (BMI, $\mathrm{kg} / \mathrm{m}^{2}$ ) before pregnancy, exposure to maternal smoking during pregnancy, gestational diabetes, gestational hypertension, preeclampsia, being the first-born child, parental educational attainment or current own BMI. The 688 participants from the ESTER study who completed the MEQ did not differ in any significant way from the 65 participants who did not complete the MEQ.

Both studies were approved by the Coordinating Ethics Committee at Helsinki and Uusimaa Hospital District. All participants gave written informed consent in accordance with the Declaration of Helsinki.

\section{Actigraphy}

Wrist-worn actigraphs were used to objectively measure sleep duration and timing. Actigraphs are well validated for measuring circadian rhythms when compared to polysomnography (Littner et al. 2003; Van De Water et al. 2011). The actigraph uses piezoelectric beams to detect movement, and records these counts digitally. If the movement count reaches a certain threshold during an epoch, an algorithm scores the epoch as awake. If the movement count does not surpass the threshold during several consecutive epochs, the algorithm considers the participant to be asleep. In both the ESTER and AYLS studies, participants documented in a sleep diary the times for going to bed and getting up, any exceptional events or nights, and any interruptions in the recording (e.g. when showering). Additionally, the participants pressed an event marker on the actigraph at bedand get up times, which helped in identifying the analysis windows for each night. In the ESTER study, we used ActiGraph GT1M (ActiGraph, LLC), with the software Actilife 4.1.1, and the Sadeh algorithm. In the AYLS, we used Actiwatch AW7 (Cambridge Neurotechnology Ltd., UK), with the software Sleep Analysis 7. 
We report the following sleep variables with these descriptions: bed time, the time when the participant closed the eyes and pressed the event marker; get up time, the time when the participant got up and pressed the event marker; actual sleep time, the sleep duration after subtracting the time awake; wake after sleep onset (WASO), the amount of time the participant is awake between falling asleep and getting up; sleep midpoint weekday, the midpoint in time between falling asleep and getting up during weekday nights (Sunday-Thursday); sleep midpoint weekend, the midpoint in time between falling asleep and getting up during weekend nights (Friday-Saturday); catch-up sleep, the difference in sleep duration between weekend- and weekday nights. Our primary outcomes were sleep midpoint during weekday and weekend nights. These two outcomes represent objectively measured sleep timing, and thus circadian preference.

The actigraphy data was scrutinized and compared with the participant's sleep diary. Individual nights were disqualified if 1) there was no activity during the registration, 2) if all documentation was missing from the sleep diary, 3) if bedtime was missing from both event markers and sleep diary, 4) if get up time was undocumented, and the event marker was not unequivocal, 5) if an aberrant activity influenced the sleep (e.g. trip), and 6) if the event markers and the sleep diary did not correspond to each other. Nights were also disqualified if the participant reported napping, drinking alcohol or taking medication that influenced sleep.

\section{Morningness-eveningness questionnaire}

The MEQ is a self-report instrument used for establishing a subjective chronotype. The questionnaire consists of 19 questions that produce a Morningness-Eveningness Score (MES), ranging from 16 to 86 . A higher score is indicative of morningness, and a lower of eveningness, with specific thresholds for the categories (42 to 58 for "intermediate"). This three-group categorization can be further divided into a "definite" morning (70 to 86 ) and evening (16 to 30 ) type. The questionnaire is validated in young adults (Horne \& Östberg 1976), and it correlates well with physiological markers of circadian rhythm, such as body temperature and melatonin level (Griefahn 2002).

\section{Background variables}

The original medical records provided the gestational age of the participants, based on ultrasonography or last menstrual period (Sipola-Leppänen et al. 2014), as well as providing information about birth weight standard deviation (SD) score, parity, maternal gestational disorders, smoking during pregnancy and BMI before pregnancy. Small for gestational age (SGA) was defined as $\leq-2$ SD for sex and length of gestation, based on Finnish birth weight standards (Pihkala et al. 1989). At the clinical visit, the participant reported the educational attainment of the higher educated parent, and the current participant BMI was calculated from measured height and weight. Self-report questionnaires provided information about daily smoking (yes/no) and the amount of paid work in a week.

\section{Statistical methods}

The participants were divided into three groups based on gestational age: for the actigraphy study 83 early preterm (<34 weeks of gestation), 165 late preterm (34 to $<37$ weeks) and 346 controls ( $\geq 37$ weeks), as defined by the American Academy of Pediatrics (Engle et al. 2007). The number of participants for the MEQ analysis was 138, 221, and 329, respectively. Also, to allow comparison with previous studies (Björkqvist et al. 2014; Strang-Karlsson et al. 2008), we separately investigated VLBW participants (actigraphy $n=33$, MEQ $n=49$ ).

Analysis of descriptive characteristics was done with t-test if the variable was continuous, and with Pearson $\chi^{2}$ if categorical. Means were calculated for sleep variables and MES. We analyzed and presented the results in three linear regression models; model 1 adjusting for age, sex and cohort; model 2 further adjusting for parental educational attainment, birth weight SD score, parity, maternal smoking during pregnancy, maternal BMI before pregnancy, gestational hypertension and diabetes; and model 3 further adjusting for participant BMI. 
Model 1 is a minimally adjusted model (Roenneberg et al. 2007), and the alternative models 2 and 3 adjust for factors related to preterm birth (Goldenberg et al. 2008) and current lifestyle. Because the two actigraph models were used exclusively in each cohort, their effect was taken into account with the cohort adjustment in model 1 . Interaction terms (sex x study group) in relation to the sleep outcomes were not significant $(p>0.2)$. 69 participants $(7 / 23 / 39)$ did not provide weekend data. To study the effect of paid employment, we analysed separately participants who reported $<20$ hours $(n=351)$ or $\geq 20$ hours $(n=243)$ of paid work during the week. As a sensitivity analysis we investigated if exclusion of participants who reported having children in the family changed the main outcomes. Additionally, we calculated sleep midpoint corrected by sleep debt MSFsc (Roenneberg et al. 2004). We analyzed distribution of both the three-group chronotype (morning/ intermediate/evening) and five-group chronotype (definite morning/moderate morning/intermediate/moderate evening/definite evening) with Pearson $\chi^{2}$. The $\alpha$-level was set to 0.05 . SPSS 22.0 was used for the statistical analyses.

\section{Results}

\section{Background characteristics}

The early and late preterm groups were compared to the control group regarding background variables (Table 1). In the pooled actigraphy data from both cohorts, the preterm participants were younger than the controls. There was no statistically significant difference in distribution of maternal smoking during pregnancy, maternal BMI before pregnancy, gestational diabetes or hypertension, being first-born, parental educational attainment, sex, current BMI or smoking. By design the early and late preterm groups were born at a lower birth weight, smaller for

Table 1. Characteristics of actigraphy study participants, $n=594$.

\begin{tabular}{|c|c|c|c|c|c|c|c|c|}
\hline & & & \multicolumn{2}{|c|}{$\begin{array}{l}\text { Control, } \\
n=346\end{array}$} & \multicolumn{2}{|c|}{$\begin{array}{l}\text { Late preterm, } \\
\qquad n=165\end{array}$} & \multicolumn{2}{|c|}{$\begin{array}{c}\text { Early preterm, } \\
n=83\end{array}$} \\
\hline & & & & Missing & & P-value & & P-value \\
\hline \multirow[t]{3}{*}{ Number of participants } & & & & $0 / 0 / 0$ & & 0.009 & & $<0.001$ \\
\hline & AYLS & $\begin{array}{l}n \text { (\% in } \\
\text { cohort) }\end{array}$ & $200(66.0)$ & & $75(24.8)$ & & $28(9.2)$ & \\
\hline & ESTER & $\begin{array}{l}n \text { (\% in } \\
\text { cohort) }\end{array}$ & $146(50.2)$ & & $90(30.9)$ & & $55(18.9)$ & \\
\hline Male & & $n(\%)$ & $150(43.4)$ & $0 / 0 / 0$ & $84(50.9)$ & 0.109 & $38(45.8)$ & 0.689 \\
\hline Gestational age, weeks & & mean (SD) & $40.14(1.18)$ & $0 / 0 / 0$ & $35.81(0.79)$ & $<0.001$ & $31.71(2.16)$ & $<0.001$ \\
\hline Birth Weight, grams & & mean (SD) & $\begin{array}{l}3589.80 \\
(488.72)\end{array}$ & $0 / 0 / 0$ & $\begin{array}{l}2711.64 \\
(547.91)\end{array}$ & $<0.001$ & $\begin{array}{l}1729.22 \\
(471.81)\end{array}$ & $<0.001$ \\
\hline Small for gestational age & & $n(\%)$ & $4(1.2)$ & $0 / 0 / 0$ & $20(12.1)$ & $<0.001$ & $14(16.9)$ & $<0.001$ \\
\hline First-born child & & $n(\%)$ & $139(40.2)$ & $0 / 0 / 0$ & $76(46.1)$ & 0.207 & $40(48.2)$ & 0.183 \\
\hline Maternal BMI before pregnancy & & mean (SD) & $22.22(2.99)$ & $5 / 2 / 0$ & $22.20(3.32)$ & 0.952 & $22.57(3.84)$ & 0.439 \\
\hline Maternal gestational diabetes & & $n(\%)$ & $8(2.3)$ & $2 / 10 / 14$ & $5(3.0)$ & 0.559 & $0(0.0)$ & 0.201 \\
\hline Maternal gestational hypertension & & $n(\%)$ & $40(11.6)$ & $16 / 8 / 1$ & $16(9.7)$ & 0.528 & $12(14.5)$ & 0.468 \\
\hline Maternal pre-eclampsia & & $n(\%)$ & $8(2.3)$ & $16 / 8 / 1$ & $22(13.3)$ & $<0.001$ & $16(19.3)$ & $<0.001$ \\
\hline Maternal smoking during pregnancy & & $n(\%)$ & $52(15.2)$ & $3 / 3 / 2$ & 29 (17.9) & 0.433 & $18(22.2)$ & 0.124 \\
\hline Participant age, years & & mean (SD) & $24.50(1.20)$ & $0 / 0 / 0$ & $24.04(1.46)$ & 0.001 & $23.98(1.53)$ & 0.004 \\
\hline \multirow[t]{2}{*}{ Participant BMI } & Men & mean (SD) & $24.30(3.60)$ & $0 / 0 / 0$ & $24.39(4.00)$ & 0.851 & $24.03(4.43)$ & 0.699 \\
\hline & Women & mean (SD) & $23.75(4.51)$ & $0 / 0 / 0$ & $22.64(4.16)$ & 0.06 & $23.79(5.95)$ & 0.952 \\
\hline Participant smoking & & $n(\%)$ & $72(21.1)$ & $5 / 4 / 0$ & $36(22.4)$ & 0.751 & $16(19.3)$ & 0.711 \\
\hline Parental education & & & & $11 / 3 / 0$ & & 0.633 & & 0.763 \\
\hline Basic & & $n(\%)$ & $26(7.8)$ & & $11(6.8)$ & & $6(7.2)$ & \\
\hline Secondary & & $n(\%)$ & $180(53.7)$ & & $82(50.6)$ & & 47 (56.6) & \\
\hline Lower-level tertiary & & $n(\%)$ & $42(12.5)$ & & $18(11.1)$ & & $7(8.4)$ & \\
\hline Upper-level tertiary & & $n(\%)$ & $87(26.0)$ & & $51(31.5)$ & & $23(27.7)$ & \\
\hline
\end{tabular}

Control $\geq 37$ weeks of gestation, late preterm 34 to $<37$ weeks of gestation, early preterm $<34$ weeks of gestation.

$P$-values were calculated with t-test if the variable was continuous, and $x^{2}$ if categorical.

$\mathrm{SD}$, standard deviation; BMI, body mass index $\left(\mathrm{kg} / \mathrm{m}^{2}\right)$. 
gestational age, and a larger proportion were exposed to maternal preeclampsia.

As described above, the participants who completed the MEQ were all from the ESTER study. The differences in background characteristics between preterm and control group participants in the MEQ participant analysis were similar to the comparison outlined above, except that the late preterm group had proportionally more first-born participants and exposure to maternal diabetes and hypertension during pregnancy than the control group (Supplemental Table 1).

\section{Objective sleep timing: early and late prematurity}

The early and late preterm groups did not differ from the controls regarding the sleep timing measured by sleep midpoint (all $p>0.14$ ), in any of the three models (Table 2). The same was true for MSFsc (all $p>0.28$ ). The only significant difference we found in any of the sleep variables was that the late preterm group had more catch-up sleep, but only in model 2 (MD $20 \mathrm{~min} 17 \mathrm{~s}, p=0.048$ ). Exclusion of 59 participants who reported having children did not impact the main outcomes.

When we studied the participants based on their working schedules $(<20$ or $\geq 20$ hours of paid work during the week), we found that in the group with more work, the late preterm participants had 25 min $12 \mathrm{~s}$ earlier bed time (model $1, p=0.028$ ) than controls. Otherwise, there were no significant differences between the two preterm groups and the control group (Supplemental Table 2A and $2 \mathrm{~B}$ ).

\section{Objective sleep timing: VLBW}

The 33 adults born preterm at VLBW had $22 \mathrm{~min}$ $8 \mathrm{~s}$ longer actual sleep time than controls (model 1 $p=0.017, p>0.62$ in models 2 and 3), and a 47 min $25 \mathrm{~s}$ longer catch-up sleep (model 1 $p=0.057$, models 2 and $3 p \leq 0.031$ ), but no association was found regarding the sleep midpoint or other sleep variables (Supplemental Table 3). Analysis of MSFsc did not reveal a significant difference either (all $p>0.47$ ).

\section{Subjective chronotype: early and late prematurity and VLBW}

Of all 688 participants who completed the MEQ, $12.4 \%$ were of morning, $65.4 \%$ of intermediate and $22.2 \%$ of evening type. $0.7 \%$ were definite morning and $3.5 \%$ definite evening types. Neither the threenor five-group distribution differed between early preterm, late preterm and control group (unadjusted $\chi^{2} p=0.98$ and $p=0.61$ ). The MES was also similar among groups, and was unaffected by adjustment for variables in our models (Supplemental Table 4; all $p>0.5$ ). Exclusion of 75 participants who reported having children did not impact the results. Furthermore, the distribution of chronotype and the MES did not differ between the VLBW-group and controls (all $p>0.69$ ).

\section{Discussion}

Our aim was to investigate if being born early or late preterm was associated with an earlier circadian preference in adult life. We used actigraphy and self-reported chronotype to obtain objective and subjective data. Against the hypothesis grounded on previous reports, we found no significant and consistent differences in the circadian preferences between the term and preterm groups, neither using actigraphy nor subjective chronotype assessment. Nor were we able to replicate previous findings of an earlier circadian preference among the group of adults born preterm at VLBW.

Previous studies have presented reasons why prematurity might be associated with an earlier sleep-wake rhythm. Many of the components that primarily drive the circadian rhythm: the retinal photoreceptors, their connections to the suprachiasmatic nucleus, key developments of the central pacemaker itself, and the efferent connections to the periphery, are matured postnatally in animal models (Brooks \& Canal 2013). The development and onset of melatonin rhythmicity depends on neuroanatomical maturation, not environmental cues. So, the transient melatonin deficiency of 2-4 months that term-born infants experience after birth is longer with preterm birth, and commencement of pineal secretion is even further postponed by possible brain insults (Jan et al. 2007). Animal models have also 
Table 2. Linear regression models of sleep variables, all participants.

\begin{tabular}{|c|c|c|c|c|c|c|c|}
\hline \multirow{2}{*}{$n=587$} & \multirow[b]{2}{*}{ Model } & \multirow[b]{2}{*}{ Units } & \multirow{2}{*}{$\frac{\text { Controls }(n=341)}{\text { Mean }(S D)}$} & \multicolumn{2}{|l|}{ Late preterm $(n=163)$} & \multicolumn{2}{|l|}{ Early preterm $(n=83)$} \\
\hline & & & & B $(95 \% \mathrm{Cl})$ & $p$ & $\mathrm{~B}(95 \% \mathrm{Cl})$ & $p$ \\
\hline \multicolumn{8}{|c|}{ Bed Time } \\
\hline & & h:min:sec & 00:09:50 (1:17:23) & & & & \\
\hline & 1 & h:min:sec & & $-0: 11: 24(-0: 26: 03$ to $0: 03: 14)$ & 0.126 & $0: 06: 43(-0: 12: 07$ to $0: 25: 34)$ & 0.484 \\
\hline & 2 & $\mathrm{~h}: \min : \mathrm{sec}$ & & $-0: 11: 34(-0: 26: 46$ to $0: 03: 38)$ & 0.136 & $0: 10: 05(-0: 10: 23$ to $0: 30: 33)$ & 0.334 \\
\hline & 3 & h:min:sec & & $-0: 10: 55(-0: 26: 05$ to $0: 04: 14)$ & 0.158 & $0: 09: 41(-0: 10: 43$ to $0: 30: 04)$ & 0.352 \\
\hline \multicolumn{8}{|c|}{ 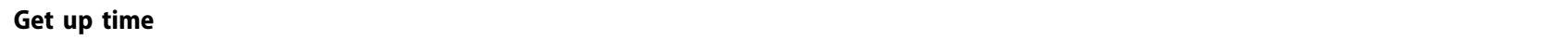 } \\
\hline & & h:min:sec & $8: 23: 55(1: 31: 30)$ & & & & \\
\hline & 1 & h:min:sec & & $-0: 09: 52(-0: 27: 03$ to $0: 07: 20)$ & 0.260 & $0: 14: 12(-0: 07: 56$ to $0: 36: 20)$ & 0.208 \\
\hline & 2 & h:min:sec & & $-0: 13: 35(-0: 31: 21$ to $0: 04: 12)$ & 0.134 & $0: 12: 26(-0: 11: 30$ to $0: 36: 22)$ & 0.308 \\
\hline & 3 & h:min:sec & & $-0: 13: 05(-0: 30: 51$ to $0: 04: 42)$ & 0.149 & $0: 12: 07(-0: 11: 47$ to $0: 36: 02)$ & 0.320 \\
\hline \multicolumn{8}{|c|}{ Actual sleep time } \\
\hline & & h:min:sec & 7:03:02 (0:51:14) & & & & \\
\hline & 1 & h:min:sec & & $0: 01: 05(-0: 08: 18$ to $0: 10: 28)$ & 0.820 & $0: 06: 38(-0: 05: 26$ to $0: 18: 43)$ & 0.281 \\
\hline & 2 & h:min:sec & & $-0: 02: 26(-0: 12: 00$ to $0: 07: 08)$ & 0.617 & $0: 01: 24(-0: 11: 29$ to $0: 14: 17)$ & 0.805 \\
\hline & 3 & h:min:sec & & $-0: 02: 47(-0: 12: 20$ to $0: 06: 46)$ & 0.567 & $0: 01: 37(-0: 11: 14$ to $0: 14: 28)$ & 0.831 \\
\hline \multicolumn{8}{|c|}{ Wake after sleep onset } \\
\hline & & h:min:sec & $0: 59: 48(0: 28: 26)$ & & & & \\
\hline & 1 & h:min:sec & & $-0: 00: 58(-0: 05: 51$ to $0: 03: 56)$ & 0.699 & $0: 01: 08(-0: 05: 10$ to $0: 07: 26)$ & 0.723 \\
\hline & 2 & h:min:sec & & $-0: 00: 39(-0: 05: 45$ to $0: 04: 27)$ & 0.803 & $0: 01: 40(-0: 05: 12$ to $0: 08: 33)$ & 0.633 \\
\hline & 3 & h:min:sec & & $-0: 00: 28(-0: 05: 34$ to $0: 04: 38)$ & 0.857 & $0: 01: 34(-0: 05: 18$ to $0: 08: 25)$ & 0.655 \\
\hline \multicolumn{8}{|c|}{ Sleep midpoint weekday } \\
\hline & & h:min:sec & 04:06:48 (1:22:06) & & & & \\
\hline & 1 & h:min:sec & & $-0: 10: 28(-0: 26: 16$ to $0: 05: 21)$ & 0.194 & $0: 11: 47(-0: 08: 34$ to $0: 32: 08)$ & 0.256 \\
\hline & 2 & h:min:sec & & $-0: 12: 19(-0: 28: 42$ to $0: 04: 04)$ & 0.141 & $0: 12: 58(-0: 09: 06$ to $0: 35: 01)$ & 0.249 \\
\hline & 3 & h:min:sec & & $-0: 11: 47(-0: 28: 10$ to $0: 04: 35)$ & 0.158 & $0: 12: 38(-0: 09: 23$ to $0: 34: 40)$ & 0.260 \\
\hline & & & Controls $(n=302)$ & Late preterm $(n=140)$ & & Early preterm $(n=76)$ & \\
\hline$n=518$ & Model & Units & Mean (SD) & B $(95 \% \mathrm{Cl})$ & $p$ & $\mathrm{~B}(95 \% \mathrm{Cl})$ & $p$ \\
\hline \multicolumn{8}{|c|}{ Sleep midpoint weekend } \\
\hline & & h:min:sec & 05:14:09 (1:32:40) & & & & \\
\hline & 1 & h:min:sec & & $-0: 01: 29(-0: 20: 36$ to $0: 17: 37)$ & 0.878 & $0: 04: 14(-0: 19: 45$ to $0: 28: 13)$ & 0.729 \\
\hline & 2 & h:min:sec & & $-0: 04: 13(-0: 24: 17$ to $0: 15: 51)$ & 0.680 & $0: 01: 33(-0: 24: 43$ to $0: 27: 49)$ & 0.908 \\
\hline & 3 & h:min:sec & & $-0: 02: 58(-0: 23: 00$ to $0: 17: 03)$ & 0.771 & $0: 01: 35(-0: 24: 36$ to $0: 27: 45)$ & 0.906 \\
\hline \multicolumn{8}{|l|}{ Catch-up } \\
\hline & & $\mathrm{h}: \min : \mathrm{sec}$ & $0: 20: 34(1: 31: 40)$ & & & & \\
\hline & 1 & h:min:sec & & $0: 18: 36(-0: 00: 29$ to $0: 37: 41)$ & 0.056 & $0: 04: 34(-0: 19: 22$ to $0: 28: 30)$ & 0.708 \\
\hline & 2 & h:min:sec & & $0: 20: 17(0: 00: 13$ to $0: 40: 20)$ & 0.048 & $0: 06: 27(-0: 19: 49$ to $0: 32: 42)$ & 0.630 \\
\hline & 3 & h:min:sec & & $0: 19: 04(-0: 00: 58$ to $0: 39: 05)$ & 0.062 & $0: 06: 25(-0: 19: 46$ to $0: 32: 35)$ & 0.631 \\
\hline
\end{tabular}

Control $\geq 37$ weeks of gestation, late preterm 34 to $<37$ weeks of gestation, early preterm $<34$ weeks of gestation.

The times shown in the early and late preterm group are relative to the time in the control group, a negative value is earlier and a positive value is later.

Model $1=$ adjusted for age, sex and cohort (AYLS, Northern Finland Birth Cohort, 1987-1989 cohort).

Model 2 = adjusted for variables in model $1+$ parental education level $(14$ missing $)+$ maternal smoking during pregnancy $(8$ missing $)+$ maternal BMI before pregnancy (7 missing) + birth weight standard deviation score + being the first-born child + maternal hypertension during pregnancy (25 missing) + maternal diabetes during pregnancy (26 missing).

Model 3 = adjusted for variables in model $2+$ participant BMI.

$\mathrm{SD}$, standard deviation; $\mathrm{Cl}$, confidence interval; $\mathrm{BMI}$, body mass index $\left(\mathrm{kg} / \mathrm{m}^{2}\right)$.

demonstrated that prenatal hypoxia (Joseph et al., 2002) and protein malnutrition (Durán et al. 2005) may induce a possible phase advance of activity. These are also characteristics of the very preterm or VLBW groups rather than those born across the whole range of preterm birth, as in the present study. Moreover, those born very preterm or at VLBW are more likely to be admitted to NICUs (Marchofdimes.org 2011), where the infant is often subjected to abnormal lighting conditions, or even continuous lighting which was the norm for our VLBW participants in the 1980s. One possible reason why we did not observe differences between groups could be that the perinatal conditions were not as disruptive for our participants, who were born across the whole range of gestational ages, as they were for the VLBW survivors in studies that have reported an earlier circadian rhythm. That we did not observe a difference between adults 
born preterm at VLBW and controls should be interpreted with caution, as our study was not powered for this smaller group.

Strengths of this study were the use of objective data which was gathered with actigraphy, avoiding recall bias. The data was collected from two separate, well-described cohorts of adult preterms of different degrees of gestational age. The average length of wearing the actigraph was almost seven days, which can be considered good. This together with the substantial number of participants resulted in adequate power; the confidence intervals in sleep midpoint between the early preterm and term groups ( -8 to $32 \mathrm{~min}$ ) and between late preterm and term groups ( -26 to $5 \mathrm{~min}$ ) indicate that we were able to exclude moderate or large differences between the study groups. Furthermore, for an $\alpha=0.05$ and $1-\beta=0.8$, even our weakest main comparison between the early preterm group $(n=83)$ and controls $(n=341)$ in the actigraphy analysis would be able to detect or exclude a mean difference of 0.34 SD. This is charitable considering that the mean effect size in studies that investigate preterm circadian preference (Asaka \& Takada 2010; Björkqvist et al. 2014; Hibbs et al. 2014; Maurer et al. 2016; Natale et al. 2005; Stangenes et al. 2017; Strang-Karlsson et al. 2008; Strang-Karlsson et al. 2010), and in adult VLBW studies in general, tend to be around the order of magnitude of $\sim 0.5$ (Hovi et al. 2007; Pyhälä et al. 2011). The few formally statistically significant differences showed no consistent pattern and are likely to have arisen by chance, or are possibly related to issues not studied here. In addition, we were able to complement the objective sleep data with information about subjective chronotype using the MEQ. As a weakness, we did not specifically ask the participants to specify work days and free days, or ask if the participant shared a bed with a partner or with children.

To summarize, we investigated if there was an observable difference in circadian preference between early and late preterm adults and controls born at term. Earlier studies have mainly focused on VLBW or very preterm groups. This study provided information about late preterm participants, who constitute the overwhelming majority of the prematurely born population (Engle et al. 2007). Contrary to our hypothesis, our analysis did not reveal any consistent findings of an earlier circadian preference or a pronounced morningness in preterm groups or subgroups among young adults. Therefore, in conclusion, we estimate that the earlier circadian preference that has been observed in those born smallest is unlikely to extend across the whole range of preterm birth.

\section{Funding}

This study was supported by grants from the Academy of Finland (SALVE program for 2009-2012 and grants 127437, 129306, 130326, 134791, 263924, 274794 and 285547), Doctoral Programme in Clinical Research, University of Helsinki, Doctoral Programme in Psychology, Learning, and Communication, University of Helsinki, Doctoral programme for Public Health, University of Tampere, the Emil Aaltonen Foundation, European Commission (Framework 5 award QLG1-CT-2000-001643, H2020-PHC-2014, 633595 (DynaHEALTH) and EU H2020-SC1-2016-2017 (LifeCycle) to MRJ, H2020 award SC1-2016-RTD-733180 RECAP), the Foundation for Pediatric Research, the Finnish Government Special Subsidiary for Health Sciences (evo), Finnish Medical Societies: Duodecim and Finska Läkaresällskapet, the Jalmari and Rauha Ahokas Foundation, the Juho Vainio Foundation, the National Graduate School of Clinical Investigation, the Novo Nordisk Foundation, the Signe and Ane Gyllenberg Foundation, the Sigrid Jusélius Foundation, the Yrjö Jahnsson Foundation, the Bundesministerium für Forschung und Technik (Federal Government of Germany, Ministry of Science and Technology) program grants PKE 4 and JUG 14 (FKZ's 0706224, 0706564, and 01EP9504), Samfundet Folkhälsan and Päivikki and Sakari Sohlberg Foundation.

\section{References}

Asaka Y, Takada S. 2010. Activity-based assessment of the sleep behaviors of VLBW preterm infants and full-term infants at around 12 months of age. Brain Dev. 32:150-55.

Björkqvist J, Paavonen J, Andersson S, Pesonen A-K, Lahti J, Heinonen K, Eriksson J, Räikkönen K, Hovi P, Kajantie E et al. 2014. Advanced sleep-wake rhythm in adults born prematurely: Confirmation by actigraphy-based assessment in the Helsinki Study of Very Low Birth Weight Adults. Sleep Med. 15(9):1101-06.

Blencowe H, Cousens S, Oestergaard MZ, Chou D, Moller AB, Narwal R, Adler A, Garcia CV, Rohde S, Say L, et al. 2012. National, regional, and worldwide estimates of preterm birth rates in the year 2010 with time trends since 1990 for selected countries: A systematic analysis and implications. The Lancet. 379(9832):2162-72.

Brooks E, Canal MM. 2013. Development of circadian rhythms: Role of postnatal light environment (review). Neurosci Biobehav Rev. 37:551-60. 
Crump C, Sundquist K, Sundquist J, Winkleby MA. 2011. Gestational age at birth and mortality in young adulthood. JAMA. 306(11):1233-40. doi:10.1001/jama.2011.1331.

Durán P, Cintra L, Galler JR, Tonkiss J. 2005. Prenatal protein malnutrition induces a phase shift advance of the spontaneous locomotor rhythm and alters the rest/activity ratio in adult rats. Nutrit Neurosci. 8(3):167-72.

Engle WA. 2011. Morbidity and mortality in late preterm and early term newborns: A continuum. Clin Perinatol. 38:493-516. doi:10.1016/j.clp.2011.06.009.

Engle WA, Tomashek KM, Wallman C. 2007. Committee on fetus and newborn, American academy of pediatrics. "Late preterm" infants: A population at risk. Pediatrics. 120:1390-401.

Goldenberg RL, Culhane JF, Iams JD, Romero R. 2008. Epidemiology and causes of preterm birth. The Lancet. 371:75-84.

Griefahn B. 2002. The validity of the temporal parameters of the daily rhythm of melatonin levels as an indicator of morningness. Chronobiol Int. 19(3):561-77.

Heinonen K, Räikkönen K, Pesonen AK, Kajantie E, Andersson S, Eriksson JG, Niemelä A, Vartia T, Peltola J, Lano A. 2008. Prenatal and postnatal growth and cognitive abilities at 56 months of age: A longitudinal study of infants born at term. Pediatrics. 121:1325-33.

Hibbs AM, Storfer-Isser A, Ievers-Landis CE, Taveras EM, Redline S. 2014. Advanced sleep phase in adolescents born preterm. Behav Sleep Med. 12:1-13.

Horne JA, Östberg O. 1976. A self-assessment questionnaire to determine morningness-eveningness in human circadian rhythms. Int J Chronobiol. 4(2):97-110.

Hovi P, Andersson S, Eriksson JG, Järvenpää A-L, StrangKarlsson S, Mäkitie O, Kajantie E. 2007. Glucose regulation in young adults with very low birth weight. N Engl J Med. 356:2053-63.

Hovi P, Vohr B, Ment LR Doyle LW, McGarvey L, Morrison KM, Evensen KAI, van der Pal S, Grunau RE, Brubakk AM. 2016. Blood pressure in young adults born at very low birth weight: Adults born preterm international collaboration. Hypertension. 68(4):880-87. doi:10.1161/ HYPERTENSIONAHA.116.08167.

Jan JE, Wasdell MB, Freeman RD, Bax M. 2007. Evidence supporting the use of melatonin in short gestation infants. J Pineal Res. 42:22-27.

Joseph V, Mamet J, Lee F, Dalmaz Y, Van Reeth O. 2002. Prenatal hypoxia impairs circadian synchronization and response of the biological clock to light in adult rats. J Physiol. 543:387-95.

Kajantie E, Strang-Karlsson S, Hovi P, Räikkönen K, Pesonen A-K, Heinonen K, Järvenpää A-L, Eriksson JG, Andersson S. 2010. Adults born at very low birth weight exercise less than their peers born at term. J Pediatr. 157(4):610-616. e611.

Littner M, Kushida CA, Anderson WM, Bailey D, Berry RB, Davila DG, Hirshkowitz M, Kapen S, Kramer M, Loube D. 2003. Practice parameters for the role of actigraphy in the study of sleep and circadian rhythms: An update for 2002.
Standards of practice committee of the american academy of sleep medicine. Sleep. 26:337-41.

Marchofdimes.org. 2011. National perinatal information system/quality analytic services. Specialty care nursery admissions. Accessed 2017 Mar 15. https://www.marchofdimes. org/peristats/pdfdocs/nicu_summary_final.pdf.

Mathewson KJ, Chow CHT, Dobson KG, Pope EI, Schmidt LA, Van Lieshout RJ. 2017. Mental health of extremely low birth weight survivors: A systematic review and meta-analysis. Psychol Bull. 143(4): 347-83. doi:10.1037/ bul0000091. Epub 2017 Feb 13.

Maurer N, Perkinson-Gloor N, Stalder T, Hagmann-von Arx P, Brand S, Holsboer-Trachsler E, Wellmann S, Grob A, Weber P, Lemola S. 2016. Salivary and hair glucocorticoids and sleep in very preterm children during school age. Psychoneuroendocrinology. 72:166-74.

Merikanto I, Lahti T, Kronholm E, Peltonen M, Laatikainen T, Vartiainen E, Salomaa V, Partonen T. 2013b. Evening types are prone to depression. Chronobiol Int. 30(5):719-25. doi:10.3109/07420528.2013.784770.

Merikanto I, Lahti T, Puolijoki H, Vanhala M, Peltonen M, Laatikainen T, Vartiainen E, Salomaa V, Kronholm E, Partonen T. 2013a. Associations of chronotype and sleep with cardiovascular diseases and type 2 diabetes. Chronobiol Int. 30:470-77.

Morrison KM, Ramsingh L, Gunn E, Streiner D, Van Lieshout R, Boyle M, Gerstein H, Schmidt L, Saigal S. 2016. Cardiometabolic health in adults born premature with extremely low birth weight. Pediatrics. 138(4): e2016515. doi:10.1542/peds.2016-0515.

Natale V, Sansavini A, Trombini E, Esposito MJ, Alessandroni R, Faldella G. 2005. Relationship between preterm birth and circadian typology in adolescence. Neurosci Lett. 382:139-42.

Nosarti C, Reichenberg A, Murray RM, Cnattingius S, Lambe MP, Yin L, MacCabe J, Rifkin L, and Hultman CM. 2012. Preterm birth and psychiatric disorders in young life. Arch Gen Psychiatry. 69(6):E1-8. doi:10.1001/archgenpsychiatry.2011.1374.

Pihkala J, Hakala T, Voutilainen P, Raivio K. 1989. Characteristic of recent fetal growth curves in Finland. Duodecim. 105(18):1540-46. Review. Finnish.

Pyhälä R, Lahti J, Heinonen K, Pesonen A-K, Strang-Karlsson S, Hovi P, Järvenpää A-L, Eriksson JG, Andersson S, Kajantie E. 2011. Neurocognitive abilities in young adults with very low birth weight. Neurology. 77:2052-60.

Riegel K, Ohrt B, Wolke D, Österlund K. 1995. Die Entwicklung gefährdet geborener Kinder bis zum funften Lebensjahr: die Arvo Ylppö-Neugeborenen-Nachfolgestudie in Sudbayern und Sudfinnland. Stuttgart: Ferdinand Enke Verlag.

Roenneberg T, Kuehnle T, Juda M, Kantermann T, Allebrandt K, Gordijn M, Merrow M. 2007. Epidemiology of the human circadian clock. Sleep Med Rev. 11(6):429-38.

Roenneberg T, Kuehnle T, Pramstaller PP, Ricken J, Havel M, Guth A, Merrow M. 2004. A marker for the end of adolescence. Curr Biol. 14(24):R1038-9. 
Salonen MK, Wasenius N, Kajantie E, Lano A, Heinonen K, Räikkönen K, Eriksson JG. 2015. Physical activity, body composition and metabolic syndrome in young adults. PLoS One. 10:e0126737.

Sipola-Leppänen $M$, Väärasmäki $M$, Tikanmäki $M$, Hovi $P$, Miettola S, Ruokonen A, Pouta A, Järvelin M-R, Kajantie E. 2014. Cardiovascular risk factors in adolescents born preterm. Pediatrics. 134:e1072-1081.

Sipola-Leppänen $M$, Väärasmaki $M$, Tikanmäki $M$, Matinolli H-M, Miettola S, Hovi P, Wehkalampi K, Ruokonen A, Sundvall J, Pouta A, et al. 2015. Cardiometabolic risk factors in young adults who were born preterm. Am J Epidemiol. 181(11):861-73.

Stangenes KM, Fevang SK, Grundt J, Donkor HM, Markestad T, Hysing M, Elgen IB, Bjorvatn B. 2017. Children born extremely preterm had different sleeping habits at 11 years of age and more childhood sleep problems than term-born children. Acta Paediatr. doi:10.1111/apa.13991. Epub ahead of print.

Strang-Karlsson S, Kajantie E, Pesonen A-K, Räikkönen K, Hovi P, Lahti J, Heinonen K, Järvenpää A-L, Eriksson JG,
Andersson S, et al. 2010. Morningness propensity in young adults born prematurely: The Helsinki study of very low birth weight adults. Chronobiol Int. 27(9-10):1829-42.

Strang-Karlsson S, Räikkönen K, Kajantie E, Andersson S, Hovi P, Heinonen K, Pesonen A-K, Järvenpää A-L, Eriksson JG, Paavonen EJ. 2008. Sleep quality in young adults born with very low birth weight - The Helsinki study of very low birth weight adults. J Pediatr Psychol. 33(4):387-95.

Van De Water AT, Holmes A, Hurley DA. 2011. Objective measurements of sleep for non-laboratory settings as alternatives to polysomnography - A systematic review. J Sleep Res. 20(1 Pt 2):183-200.

Wennman H, Kronholm E, Partonen T, Peltonen M, Vasankari T, Borodulin K. 2015. Evening typology and morning tiredness associates with low leisure time physical activity and high sitting. Chronobiol Int. 32 (8):1090-100.

Wong PM, Hasler BP, Kamarck TW, Muldoon MF, Manuck SB. 2015. Social jetlag, chronotype and cardiometabolic risk. J Clin Endocrinol Metab. 100(12):4612-20. 